\title{
Clinical Characteristics of Adult Hemophagocytic Lymphohistiocytosis in the Emergency Department
}

\author{
Fang-Jie Zhang (D) \\ Guo-Qing Huang \\ Jia $\mathrm{Li}$ \\ Ji Xu \\ Xiang-Min Li \\ Ai-Min Wang
}

Department of Emergency Medicine, Xiangya Hospital, Central South

University, Changsha, Hunan, 4I0008,

People's Republic of China
Correspondence: Xiang-Min Li; Ai-Min Wang

Department of Emergency Medicine, Xiangya Hospital, Central South University, 87 Xiangya Road, Changsha, Hunan, 410008, People's Republic of China

Tel +86/3875858068; +86/3875927399

Email Ixm8229@।26.com;

wangaimin@csu.edu.cn
Purpose: To determine the clinical manifestations and results of adult hemophagocytic lymphohistiocytosis (HLH) patients in our emergency department.

Methods: We retrospectively evaluated patients with HLH from 1 April 2018 to 31 December 2020. The clinical data of these patients (basic information, symptoms, vital signs, laboratory results, HLH diagnostic criteria, H Score, main treatments, outcomes) were collected.

Results: Thirty-three patients ( 23 males and 10 females; $40.55 \pm 18.78$ years) with 34 clinical episodes (one male had two clinical episodes and died during the second episode) were enrolled. Twenty-five patients were placed in a "survivor" group, and nine patients were categorized into a "deceased" group. Fever, splenomegaly, hemoglobin $<90 \mathrm{~g} / \mathrm{L}$ and platelet count $<100 \times 10^{9} / \mathrm{L}$ most commonly met the diagnostic standard for HLH. The H Score results in the survival group and deceased group was $212.4 \pm 37.18$ and $252.1 \pm 40.95$, respectively. Viral infection was the most common reason for HLH, followed by immune-system disease and cancer. Laboratory tests showed that deceased-group patients had multiple-organ dysfunction. Multivariate logistic regression showed that the lactate dehydrogenase (lactate dehydrogenase) level ( $\mathrm{P}=0.039$; odds ratio, 0.999$)$ was significantly related to death.

Conclusion: In the emergency department, HLH should be considered for critically ill patients with fever, splenomegaly, low hemoglobin and low platelet count. The H Score might be useful to diagnose HLH quickly. In our study, $26.47 \%$ of HLH patients died in the emergency department, and patients with a significantly increased lactate dehydrogenase level had a markedly increased risk of death.

Keywords: clinical characteristics, hemophagocytic lymphohistiocytosis, emergency department, mortality, lactate dehydrogenase

\section{Introduction}

Hemophagocytic lymphohistiocytosis (HLH, also termed "hemophagocytic syndrome") is a rare, immune-mediated life-threatening disease with an estimated yearly incidence in Japan of $1 / 800,000$ people. ${ }^{1}$ HLH is a group of clinical syndromes with various symptoms, involves multiple tissues and organs, and is caused by primary or acquired immune abnormalities. ${ }^{2}$ A pathologic feature of HLH is a nonspecific "storm" of proinflammatory cytokines such as interferon- $\gamma$, interleukin (IL)-1, and IL-6, and the compensatory downregulating cytokine IL-10 activating macrophages, natural killer (NK) cells, and cytotoxic $\mathrm{T}$ lymphocytes to mediate damage to multiple tissues and organs. ${ }^{3,4}$ Eventually, the natural course of 
HLH leads to multiple-organ dysfunction, and the main clinical manifestations are persistent fever, hepatomegaly, splenomegaly, pancytopenia, coagulopathy, and hemophagocytosis in the bone marrow, liver, spleen, and lymphnode tissues. ${ }^{5}$ Unfortunately, only $10 \%$ of HLH patients survive if they do not receive immunochemotherapy; ${ }^{4}$ the overall mortality rate of all reason caused HLH is $26.5 \%$ to $74.8 \%{ }^{6}{ }^{6}$ however, in study with main malignancy related $\mathrm{HLH}$, the mortality will be higher than in study with more infectious/autoimmune $\mathrm{HLH}^{6}{ }^{6}$ and $30.8 \%$ die rapidly within 2 months after diagnosis even when the patients receive chemotherapy. ${ }^{7}$

HLH was first recognized to be familial in infants in 1952. ${ }^{8}$ However, although most cases are children, it has been demonstrated that HLH can occur at any age, and $40 \%$ of HLH cases occur in adults. ${ }^{1}$ Therefore, most clinical guidelines and clinical trials have focused on pediatric patients. Also, the diagnostic and therapeutic guidelines for the pediatric HLH-2004 protocol have also been adopted widely in adult patients with HLH. ${ }^{9}$

Traditionally, HLH has been divided into primary (genetic) and secondary (reactive) subtypes according to the cause of disease. Secondary causes are subclassified as infection (most are viral), autoimmune, or tumor-related. ${ }^{2}$ However, some degree of genetic predisposition may also be implicated in secondary HLH because monoallelic mutations or polymorphisms of genes have been detected in some patients with classical secondary HLH. ${ }^{10}$ Most cases of HLH in adults for which a clear trigger can be identified are associated with a secondary cause, ${ }^{11}$ and familial HLH may be also triggered by infection or autoimmune disease. ${ }^{12}$

HLH can involve multiple tissues and organs and has various symptoms, so obtaining a rapid and accurate diagnosis at the early stage is difficult because HLH patients mostly have high fever, fatigue caused by anemia, bleeding tendency (eg, gastrointestinal) and skin ecchymosis. Initially, HLH patients may visit the emergency department (emergency department) for medical help and then be transferred to a specialist ward. However, no study has reported the clinical manifestations and treatment results of adult HLH patients in the emergency department, and we sought to bridge this gap in the literature.

\section{Methods}

\section{Ethical Approval of the Study Protocol}

The study protocol was approved (202101020) by the ethics committee of Xiangya Hospital of Central South
University (Changsha, China). The study protocol complied with the guidelines enshrined in the Declaration of Helsinki 1964 and its later amendments. The data in the present study were retrospective and anonymous, so the requirement for written informed consent was waived.

\section{Study Design}

We retrospectively evaluated patients with $\mathrm{HLH}$ admitted to the Department of Emergency Medicine in Xiangya Hospital of Central South University from 1 April 2018 to 31 December 2020. Enrolled patients were those diagnosed with HLH for the first time in our emergency department or had a confirmed diagnosis with acute severe illness that necessitated urgent treatment in our emergency department.

\section{Diagnostic Criteria}

All enrolled patients satisfied the established diagnostic criteria for $\mathrm{HLH}^{9}{ }^{9}$ (1) a molecular diagnosis consistent with the pathologic mutations of PRF1, UNC13D, STXBP1, RAB27A, STX11, SH2D1A, or XIAP; (2) meeting five of the following criteria: (i) body temperature $\geq 38.5^{\circ} \mathrm{C}$; (ii) splenomegaly; (iii) cytopenia affecting at least two of three cell lineages in peripheral blood, ie, hemoglobin $<90 \mathrm{~g} / \mathrm{L}$, platelet count $<100 \times 10^{9} / \mathrm{L}$, neutrophil count $<1 \times 10^{9} / \mathrm{L}$; (iv) triglycerides $\geq 3 \mathrm{mmol} / \mathrm{L}$ and $/$ or fibrinogen $\leq 1.5 \mathrm{~g} / \mathrm{L}$; (v) hemophagocytosis in the bone marrow, spleen, lymph nodes, or liver; (vi) low or absent activity of NK cells; (vii) ferritin $\geq 500 \mu \mathrm{g} / \mathrm{L}$; (viii) soluble cluster of differentiation (CD) 25 (ie, soluble IL-2) $\geq 2400$ $\mathrm{U} / \mathrm{mL}$ or $\geq 6400 \mathrm{pg} / \mathrm{mL}$.

The clinical diagnosis was HLH, and patients were hospitalized in the Department of Hematology or Department of Infectious Diseases within our hospital. Those who did not meet the five diagnostic criteria stated above when they stayed in our emergency department (eg, due to NK-cell activity, CD25 level could not be tested in our hospital, or we did not follow-up the results after hospitalization in the specialist ward) were not enrolled in this study, and we also calculated the H Score. ${ }^{13}$

\section{Data Collection}

Clinical data were collected: basic information (age, sex, duration of emergency department stay); symptoms; vital signs; laboratory results; whether they met the diagnostic criteria for HLH; main treatments; outcomes. Vital signs comprised body temperature, heart rate, respiratory rate, systolic blood pressure, diastolic blood pressure, and 
level of consciousness. Laboratory tests upon hospital admission comprised counts (white blood cells, red blood cells, hemoglobin, platelets, neutrophils), prothrombin time, activated partial prothrombin time, as well as levels of fibrinogen, fibrinogen-degradation products, D-dimer, albumin, total bilirubin, direct bilirubin, alanine aminotransferase, aspartate aminotransferase, serum creatinine, blood urea nitrogen, lactate dehydrogenase, cholesterol, and triglycerides. Data for all vital signs and laboratory results were the worst results taken within $24 \mathrm{~h}$ of hospital admission. We also collected imaging data (especially for diagnosing splenomegaly) and results for bone-marrow aspiration. The activity of NK cells, the CD25 level and pathology results of bonemarrow biopsy were tested by Kindstar Global Corporation (Beijing, China).

\section{Patient Grouping}

We divided patients into a "survivor" group and "deceased" group in our emergency department. The latter included patients who had: (i) died in our emergency department; (ii) a significant and stubborn decrease in blood pressure despite administration of high doses of dopamine $(>15 \mu \mathrm{g} / \mathrm{kg} / \mathrm{min})$ and/or norepinephrine $(>0.1$ $\mu \mathrm{g} / \mathrm{kg} / \mathrm{min}$ ); (iii) severe mental disorders with severe metabolic acidosis $(\mathrm{pH}<7.0)$ or fulminant liver failure or severe gastrointestinal bleeding and hematemesis; (iv) respiratory failure despite invasive ventilator-assisted breathing with pure oxygen; (v) experienced cardiac arrest and were alive after cardiopulmonary resuscitation but remained unconscious and had hypotension and arrhythmia. Patients with the irreversible manifestations described above were deemed to be facing death. The illness was discussed with the guardian/authorized principal of the patient. If the guardian/authorized principal refused treatment and asked for the patient to be discharged from hospital and the patient died within several hours after hospital discharge according to follow-up by telephone, they were deemed to be deceased.

The survivor group comprised patients: (i) whose condition was obviously better than at the time of hospital admission; (ii) whose vital signs were normal/approximately normal and who did not require dopamine, norepinephrine or artificial ventilation; (iii) who were transferred to a specialist ward in our hospital (or another hospital) for the next stage of treatment; (iv) who were alive within 24 $\mathrm{h}$ after discharge from our emergency department according to follow-up by telephone. There was no follow-up of the medication or clinical results of patients after admission to a specialist ward or another hospital.

\section{Statistical Analyses}

Data were analyzed using Prism 5 (GraphPad, San Diego, CA, USA) and SPSS 17.0 (IBM, Armonk, NY, USA). Data are the mean \pm SD. Comparisons of measurement data were made with Student's $t$-tests, whereas comparisons of enumeration data were made with chi-square tests. Multivariate logistic regression analyses were undertaken to identify independent factors related to the deceased group. The threshold for entry of variables into the multivariate model was $\mathrm{P}<0.01$. Odds ratios and 95\% confidence intervals were also calculated. $\mathrm{P}<0.05$ was considered significant.

\section{Results}

\section{Clinical Characteristics and Underlying Disease}

Thirty-three patients (23 males (69.70\%) and 10 females; $40.55 \pm 18.78$ years) with 34 clinical episodes (one male had two clinical episodes and died during the second episode) were enrolled. Twenty-five patients (16 males and nine females; 21 patients were in their first episode) were divided into a survivor group $(39.16 \pm 18.58$ years; range: 16-75 years). Nine patients (eight males and one female; six patients were in their first episode) were divided into a deceased group ( $45.33 \pm 18.76$ years; range: $16-70$ years $)$. The sex, age, prevalence of first episode and days remaining in the emergency department were not significantly different (Table 1). With respect to vital signs, the heart rate, respiratory rate, and prevalence of patient confusion showed significant differences, yet temperature, systolic blood pressure, diastolic blood pressure and the prevalence of bleeding manifestations were not significantly different (Table 1).

We also determined the total number of HLH diagnostic criteria met in all patients (Table 1). Fever, splenomegaly, hemoglobin $<90 \mathrm{~g} / \mathrm{L}$ and platelet count $<100 \times 10^{9} / \mathrm{L}$ were the most commonly met standards. Subsequently, ferritin $\geq 500 \mu \mathrm{g} /$ $\mathrm{L}$, neutrophil count $<1 \times 10^{9} / \mathrm{L}, \mathrm{CD} 25$, triglyceride $\geq 3 \mathrm{mmol} / \mathrm{L}$, fibrinogen $\leq 1.5 \mathrm{~g} / \mathrm{L}$, and NK-cell activity was documented in more than half of patients; hemophagocytosis was observed in 10 patients $(30 \%)$.

Tests were undertaken to determine the underlying disease (Table 1). Viral infection (15 patients) was the most common reason for HLH, followed by immune-system 
Table I Clinical Manifestations in Survivor and Deceased HLH Patients

\begin{tabular}{|c|c|c|c|}
\hline & Survivor $(n=25)$ & Deceased $(n=9)$ & $\mathbf{P}$ \\
\hline Male (\%) & $16(64 \%)$ & $8(88.89 \%)$ & 0.2250 \\
\hline First episode & 21 & 6 & 0.3482 \\
\hline Days stayed in emergency department & $3.883 \pm 5.629$ & $3.808 \pm 5.629$ & 0.9626 \\
\hline Age (years) & $39.16 \pm 18.58$ & $45.33 \pm 18.76$ & 0.4001 \\
\hline Temperature $\left({ }^{\circ} \mathrm{C}\right)$ & $39.25 \pm 1.214$ & $39.42 \pm 0.805$ & 0.6932 \\
\hline Pulse rate $(/ \mathrm{min})$ & $121.0 \pm 19.69$ & $138.1 \pm 21.13$ & 0.0352 \\
\hline Respiratory rate (/min) & $27.76 \pm 8.084$ & $34.00 \pm 7.089$ & 0.0491 \\
\hline Systolic blood pressure (mmhg) & $89.52 \pm 16.68$ & $88.78 \pm 35.99$ & 0.9346 \\
\hline Diastolic blood pressure (mmhg) & $50.00 \pm 10.82$ & $49.11 \pm 19.82$ & 0.8679 \\
\hline Confusion & I & 4 & 0.0118 \\
\hline Bleeding manifestations & 12 & 8 & 0.0504 \\
\hline \multicolumn{4}{|l|}{ Met the HLH diagnostic criteria } \\
\hline Fever & 24 & 9 & 1.0000 \\
\hline Splenomegaly & 24 & 7 & 0.1644 \\
\hline Hemoglobin $<90 \mathrm{~g} / \mathrm{L}$ & 24 & 8 & 0.4652 \\
\hline Platelet $<100 * 10^{9} / \mathrm{L}$ & 24 & 9 & 1.0000 \\
\hline Neutrophils $<1 * 10^{9} / \mathrm{L}$ & 15 & 6 & 1.0000 \\
\hline Triglycerides $\geq 3 \mathrm{mmol} / \mathrm{L}$ & 14 & 5 & 1.0000 \\
\hline Fibrinogen $\leq 1.5 \mathrm{~g} / \mathrm{L}$ & 12 & 7 & $0.240 \mathrm{I}$ \\
\hline Hemophagocytosis & 8 & 2 & 0.6921 \\
\hline Ferritin $\geq 500 \mu \mathrm{g} / \mathrm{L}$ & 19 & 7 & 1.0000 \\
\hline Low or absent natural killer-cell activity & 12 & 5 & 1.0000 \\
\hline Soluble CD25 $\geq 2400 \mathrm{U} / \mathrm{mL}$ or $6400 \mathrm{pg} / \mathrm{mL}$ & 15 & 5 & 1.0000 \\
\hline H Score & $212.4 \pm 37.18$ & $252.1 \pm 40.95$ & 0.0115 \\
\hline \multicolumn{4}{|l|}{ Underlying diseases } \\
\hline Viral infection & $12 \mathrm{EBV}+\mathrm{ICMV}$ & $2 \mathrm{EBV}$ & $0.240 \mathrm{I}$ \\
\hline Systemic lupus erythematosus & $\mathrm{I}$ & 0 & 1.0000 \\
\hline Autoimmune hemolytic anemia & 3 & 1 & 1.0000 \\
\hline Other autoimmune related disease & 2 & 1 & 1.0000 \\
\hline Tumor & 5 & 2 & 1.0000 \\
\hline Lymphoma & 2 & 1 & \\
\hline Histocyticsarcoma & 1 & 1 & \\
\hline Prostate cancer & 1 & 0 & \\
\hline Laryngeal Cancer & 1 & 0 & \\
\hline Uncertain & 4 & 3 & 0.3058 \\
\hline
\end{tabular}

disease (eight patients), and cancer (seven patients). However, the reason for HLH could not be determined for seven patients in our emergency department. Importantly, three patients in the survivor group had two underlying diseases concomitantly (autoimmune hemolytic anemia with cytomegalovirus infection; autoimmune hemolytic anemia with infection by the Epstein-Barr virus; systemic lupus erythematosus combined with idiopathic immune thrombocytopenic purpura).

\section{Laboratory Tests}

Table 2 shows the laboratory-test results in the survivor group and deceased group. We documented significant differences in markers of renal function (blood urea nitrogen), liver function (total bilirubin, direct bilirubin and aspartate aminotransferase), coagulation function (prothrombin time, activated partial prothrombin time, fibrinogen and D-dimer) and infection (procalcitonin and lactate dehydrogenase) between the two groups. 
Table 2 Laborary Test Results in Survivor and Deceased HLH Patients

\begin{tabular}{|c|c|c|c|}
\hline Laboratory Test (Normal Range) & Survivor $(n=25)$ & Deceased $(n=9)$ & $\mathbf{p}$ \\
\hline White blood cells $\left(3.5-9.5 * 10^{9} / \mathrm{L}\right)$ & $2.682 \pm 2.745$ & $3.078 \pm 2.431$ & 0.7058 \\
\hline Red blood cells $\left(4.3-5.8^{*} 10^{12} / \mathrm{L}\right)$ & $2.540 \pm 0.6058$ & $2.730 \pm 0.6546$ & 0.4351 \\
\hline Hemoglobin $(130-175 g / L)$ & $72.40 \pm 15.73$ & $77.67 \pm 13.87$ & 0.3821 \\
\hline Platelet $\left(125-350 * 10^{9} / \mathrm{L}\right)$ & $39.88 \pm 46.78$ & $19.89 \pm 13.90$ & 0.2199 \\
\hline Neutrophil $\left(1.8-6.3 * 10^{9} / \mathrm{L}\right)$ & $1.596 \pm 2.249$ & $1.733 \pm 2.080$ & 0.8739 \\
\hline Albumin $(40-55 g / L)$ & $26.94 \pm 4.770$ & $26.69 \pm 12.08$ & 0.9313 \\
\hline Blood urea nitrogen (3.6-9.5umol/L) & $8.792 \pm 4.924$ & $|3.4| \pm 4.99 \mid$ & 0.0222 \\
\hline Serum creatinine $(4|-| I I$ umol/L) & $94.47 \pm 72.32$ & $141.6 \pm 61.97$ & 0.0922 \\
\hline Total bilirubin (I.7-I7.I umol/L) & $36.50 \pm 36.10$ & $95.06 \pm 80.37$ & 0.0058 \\
\hline Direct bilirubin $(0-6.8$ umol/L) & $19.10 \pm 20.84$ & $55.49 \pm 47.89$ & 0.0038 \\
\hline Lactate dehydrogenase (120-250U/L) & $961.0 \pm 930.2$ & $3609 \pm 2840$ & 0.0003 \\
\hline Alanine aminotransferase (9-50U/L) & $197.4 \pm 523.5$ & $300.2 \pm 230.8$ & 0.5758 \\
\hline Aspartate aminotransferase (I5-40U/L) & $238.9 \pm 492.7$ & $680.4 \pm 570.2$ & 0.0341 \\
\hline Cholesterol $(<5.18 \mathrm{mmol} / \mathrm{L})$ & $2.331 \pm 0.8458$ & $2.876 \pm 1.697$ & 0.2262 \\
\hline Triglyceride $(<1.7 \mathrm{mmol} / \mathrm{L})$ & $3.200 \pm 1.123$ & $4.144 \pm 2.173$ & 0.1096 \\
\hline Prothrombin time (10-16S) & $16.76 \pm 3.984$ & $25.41 \pm 11.18$ & 0.0022 \\
\hline Activated partial prothrombin time (25-43s) & $44.44 \pm 9.985$ & $151.5 \pm 229.9$ & 0.0260 \\
\hline Fibrinogen $(2-4 g / L)$ & $2.147 \pm 2.147$ & $1.218 \pm 0.6518$ & 0.0384 \\
\hline Fibrinogen degradation products $(0-5 \mathrm{mg} / \mathrm{L})$ & $2.147 \pm 44.22$ & $64.49 \pm 36.68$ & 0.0577 \\
\hline D-dimer $(0-0.5 \mathrm{mg} / \mathrm{L})$ & $2.305 \pm 2.108$ & $5.328 \pm 3.777$ & 0.0064 \\
\hline Procalcitonin $(<0.05 \mathrm{ng} / \mathrm{mL})$ & $6.178 \pm 23.32$ & $36.07 \pm 54.86$ & 0.0406 \\
\hline
\end{tabular}

\section{Treatment}

Table 3 shows the main treatments undertaken in the survivor group and deceased group. Patients received glucocorticoids, antibiotics, antifungal drugs and antiviral drugs as basic treatment. According to disease severity, patients also received etoposide, immunoglobulins, dopamine combined with/without norepinephrine, blood purification and mechanical ventilation. There was no significant difference in treatment measures between the two groups.

\section{Outcomes and Factors Associated with Mortality}

Multivariate logistic regression analyses were undertaken to determine the independent factors related to the deceased group. The laboratory test results showed that several parameters were significantly different so, due to the relatively small sample size and some parameters reflecting the same organ function, the threshold for entry of variables into the multivariate model was $\mathrm{P}<0.01$. The results of multivariate logistic regression analyses are shown in Table 4 . We found that the lactate dehydrogenase level was significantly related to death $(\mathrm{P}=0.039$; odds ratio, 0.999).

\section{Discussion}

Adult HLH has been reported to occur mainly in middleaged ( $\sim 0$ years) male patients. ${ }^{2,14}$ Our data are in accordance with that trend: $69.70 \%$ of patients were male; in the deceased group, $88.89 \%$ were male; the median age of all patients was 38 years. We demonstrated that sex and age had no relationship with the prognosis of patients with HLH. One study showed that globally the most common cause of HLH was infection (especially infection with the Epstein-Barr virus), followed by cancer and autoimmune diseases: ${ }^{2}$ our results were in accordance with those data. However, several other studies carried out in China concluded that cancer might be the primary reason for HLH. ${ }^{15,16}$ In a retrospective analysis in several centers in China, the most common causes were of HLH were infections in the child group, malignancies and infections in the youth group, malignancies in the middle-aged group, and malignancies in the elderly group. ${ }^{17}$ The reasons for the difference between our data and those results might be: (i) our study cohort was small; (ii) the patients in other studies were from the Department of Hematology, whereas we analyzed data only from the emergency department. Our study also indicated that almost all HLH patients had fever, splenomegaly, hemoglobin $<90 \mathrm{~g} / \mathrm{L}$ and platelet count $<100 \times 10^{9} / \mathrm{L}$; for fever, hemoglobin and platelet 
Table 3 Main Treatments in Survivor and Deceased HLH Patients

\begin{tabular}{|c|c|c|c|}
\hline Treatment & $\begin{array}{l}\text { Survivor } \\
(n=25)\end{array}$ & $\begin{array}{l}\text { Deceased } \\
(n=9)\end{array}$ & $\mathbf{P}$ \\
\hline Ventilator used & 3 & 3 & \multirow[t]{21}{*}{ All $P>0.05$} \\
\hline Blood purification & 2 & 0 & \\
\hline \multicolumn{3}{|l|}{ Immunosupressive drug } & \\
\hline Glucocorticoid & 16 & 7 & \\
\hline Immunoglobulin & 4 & 1 & \\
\hline \multicolumn{3}{|l|}{ Vasoactive drugs } & \\
\hline $\begin{array}{l}\text { Dopamine combined } \\
\text { with Norepinephrine }\end{array}$ & 0 & 3 & \\
\hline Dopamine or & 2 & 4 & \\
\hline \multirow{2}{*}{\multicolumn{3}{|c|}{ Antimicrobial treatment }} & \\
\hline & & & \\
\hline Meropenem & 11 & 2 & \\
\hline Imipenem and cilastatin & 7 & 4 & \\
\hline Linezolid & I & I & \\
\hline Doxycycline & I & 2 & \\
\hline Cefotaxime & 0 & 1 & \\
\hline Piperacillin Sodium & 0 & 1 & \\
\hline \multicolumn{3}{|l|}{ Tazobactam } & \\
\hline Moxifloxacin & I & 0 & \\
\hline Antifungal drugs & 7 & 3 & \\
\hline Anti-viral drugs & 8 & 4 & \\
\hline Etoposide & 2 & 1 & \\
\hline
\end{tabular}

decreased related symptoms, such as tiredness and bleeding manifestations. These symptoms are common in the emergency department. However, because of the atypical symptoms of HLH disease, the diagnosis is difficult, and some patients experience a sharp deterioration before the diagnosis has been made, which can lead to death. Thus, the actual incidence of HLH may be higher than reported. ${ }^{18}$

We also showed that NK-cell activity, neutrophil count, as well as the level of ferritin, CD25, triglycerides, and fibrinogen were high in more than half of patients.

Table 4 Multivariate Logistic Regression Models for Independent Factors Related to HLH Death Patients

\begin{tabular}{|l|l|l|l|}
\hline Laboratory Test & OR & $\mathbf{9 5 \%} \mathbf{C l}$ & $\mathbf{P}$ \\
\hline Direct bilirubin & 0.970 & $0.922-1.020$ & 0.234 \\
Lactate dehydrogenase & 0.999 & $0.998-1.000$ & 0.039 \\
Aspartate aminotransferase & 1.000 & $0.998-1.003$ & 0.740 \\
Prothrombin time & 0.900 & $0.672-1.207$ & 0.483 \\
\hline
\end{tabular}

Unfortunately, in China, many hospitals cannot measure NK-cell activity or CD25 tests, so they send them to private organizations for testing, which limits the rapid diagnosis of HLH. Hemophagocytosis was detected in $30 \%$ of our patients; this low prevalence might be associated with the bone-marrow results not being provided on the same day. The results for many patients became available after they had left the emergency department and, in our hospital, the bone-marrow results cannot be displayed directly in the electronic medical record with laboratory and imaging data.

HLH is a severe hyperinflammatory syndrome commonly triggered by infections or malignancies, but may also be induced by autoimmune disorders. Treatment algorithms mainly include the HLH-94 and HLH-2004 protocols. ${ }^{19}$ Etoposide (VP-16), glucocorticoid drugs and hematopoietic stem-cell transplantation are the cornerstones of HLH treatment. ${ }^{19,20}$ However, in our study, most HLH patients received glucocorticoids, and only three patients with recurrent HLH received etoposide. The main reason was that many patients did not have a confirmed diagnosis upon emergency department admission. When they were admitted to the emergency department and when they were diagnosed with HLH, they were transferred to a specialist ward for subsequent treatment. In our emergency department, patients received powerful supportive treatments. Almost all patients (except those who stayed for only a few hours) received high-grade antibiotics, antifungal drugs and antiviral drugs. Some patients received immunoglobulins, some received dopamine and/or norepinephrine to maintain blood pressure, and a few patients received blood purification and ventilator-assisted breathing if they were critically ill. In the emergency department, powerful support measures were crucial due to the frequent life-threatening presentation, and administration of antimicrobial drugs that could eliminate the triggers (mainly infection) was pivotal to remove the stimuli that initiate immune disorders and to inhibit inflammation and cell proliferation (ie, neoplasia). ${ }^{2}$

Several studies have reported the predictors of mortality in adult HLH. In 293 cases of adult secondary HLH, during a median follow-up of 52 days, $70.99 \%$ of patients died, and the plasma fibrinogen level was nonlinearly and inversely associated with the risk of mortality in adult secondary HLH. ${ }^{21}$ In sixty-four adults with HLH in Latin America, patients with nosocomial infections and neurologic symptoms had significantly shorter 3-year overall survival. ${ }^{22}$ In a series of 62 adults with secondary HLH, 
patients with low serum albumin levels and tumorassociated HLH had markedly shorter survival. ${ }^{23}$ However, almost all studies analyzed the long-term prognosis of HLH patients, but not the mortality rate in the emergency department. Although powerful supportive treatments were used, nine patients $(26.47 \%$ of all patients) died in the emergency department due to critical illness. Our results indicated that deceased HLH patients had significantly worse multiple-organ dysfunction than survivors. Our multivariate logistic regression analyses showed that increased levels of lactate dehydrogenase were significantly related to death. Studies have demonstrated that lactate dehydrogenase is associated with worse outcomes in patients with viral infections and persistent organ failure. ${ }^{24-26}$ lactate dehydrogenase is a key enzyme of anaerobic metabolism that is present widely in human tissues, with high content in the kidney, myocardium and bone muscle. The lactate dehydrogenase level in red blood cells is $\sim 100$-times that in serum, and lactate dehydrogenase is also a "functional checkpoint" for anaerobic glycolysis of sugar and gluconeogenesis. ${ }^{27}$ All of the patients who died in our study had multiple-organ dysfunction, and these changes led to increased lactate dehydrogenase levels.

The H Score in the survival group and deceased group was $212.4 \pm 37.18$ and $252.1 \pm 40.95$, respectively. In a study involving $40 \mathrm{HLH}$ patients, the HLH-2004 criteria and $\mathrm{H}$ Score showed good diagnostic accuracy. Both could be used for the diagnosis of HLH in critically ill patients. The H-score cutoff value of 168 indicated that the sensitivity of diagnosing HLH was $100 \%$, and the specificity was $94.1 \%$, and the diagnostic accuracy was slightly higher than that for HLH-2004 criteria. $^{28}$ As stated above, NK-cell activity and CD25 tests cannot be done in most hospitals in China. Therefore, for critically ill patients in the emergency department, calculating the $\mathrm{H}$ score can enable testing for HLH rapidly. For HLH patients with high lactate dehydrogenase levels or multiple-organ dysfunction, aggressive life-support treatment is indicated immediately (blood purification, high-grade antibiotics or antiviral drugs, stabilization of blood pressure, high-dose glucocorticoid treatment) to reduce the risk of death.

Our study had three main limitations. First, we analyzed only the data of patients in the emergency department and did not follow-up patient status after admission to a specialist ward. Second, we did not compare the ferritin level between the two groups because the ferritin results only stated
"> $1500 \mu \mathrm{g} / \mathrm{L} "$ without an exact value being given, whereas other patients' ferritin results showed exact values because they were measured in different laboratories. Third, we did not compare the CD25 data between the two groups because the CD25 level was provided in two units (U/mL and pg/ $\mathrm{mL}$ ), so the comparison could not be standardized.

\section{Conclusions}

In the emergency department, for critically ill patients with fever, splenomegaly, low hemoglobin level and low platelet count, HLH is a possibility. The $\mathrm{H}$ score might be useful to diagnose HLH rapidly. In our study, $26.47 \%$ of HLH patients died in the emergency department, and patients with significantly increased lactate dehydrogenase levels had an increased risk of death.

\section{Data Sharing Statement}

All data generated or analyzed during this study are included in the manuscript.

\section{Consent for Publication}

All authors have approved the manuscript for submission.

\section{Funding}

This work was supported by the National Natural Science Foundation of China (81501923) and the Rui E (Ruiyi) Emergency Medical Research Special Funding Project (R2019007).

\section{Disclosure}

The authors declare that there are no conflicts of interest.

\section{References}

1. Ishii E, Ohga S, Imashuku S, et al. Nationwide survey of hemophagocytic lymphohistiocytosis in Japan. Int $J$ Hematol. 2007;86 (1):58-65. doi:10.1532/IJH97.07012

2. Ramos-Casals M, Brito-Zeron P, Lopez-Guillermo A, Khamashta MA, Bosch X. Adult haemophagocytic syndrome. Lancet. 2014;383 (9927):1503-1516. doi:10.1016/S0140-6736(13)61048-X

3. Brisse E, Wouters $\mathrm{CH}$, Matthys P. Hemophagocytic lymphohistiocytosis (HLH): a heterogeneous spectrum of cytokine-driven immune disorders. Cytokine Growth Factor Rev. 2015;26(3):263-280. doi:10.1016/j.cytogfr.2014.10.001

4. Allen CE, McClain KL. Pathophysiology and epidemiology of hemophagocytic lymphohistiocytosis. Hematology Am Soc Hematol Educ Program. 2015;2015:177-182. doi:10.1182/asheducation-2015.1.177

5. Risma KA, Marsh RA. Hemophagocytic lymphohistiocytosis: clinical presentations and diagnosis. J Allergy Clin Immunol Pract. 2019;7 (3):824-832. doi:10.1016/j.jaip.2018.11.050

6. Yildiz H, Van Den Neste E, Defour JP, Danse E, Yombi JC. Adult haemophagocytic lymphohistiocytosis: a review. QJM. 2020. doi:10.1093/qjmed/hcaa011. Online ahead of print. 
7. Song Y, Pei RJ, Wang YN, Zhang J, Wang Z. Central nervous system involvement in hemophagocytic lymphohistiocytosis in adults: a retrospective analysis of 96 patients in a single center. Chin Med J (Engl). 2018;131(7):776-783. doi:10.4103/0366-69 99.228234

8. Farquhar JW, Claireaux AE. Familial haemophagocytic reticulosis. Arch Dis Child. 1952;27(136):519-525. doi:10.1136/adc.27.136. 519

9. Henter JI, Horne A, Arico M, et al. HLH-2004: diagnostic and therapeutic guidelines for hemophagocytic lymphohistiocytosis. Pediatr Blood Cancer. 2007;48(2):124-131. doi:10.1002/pbc.21039

10. Brisse E, Wouters $\mathrm{CH}$, Matthys P. Advances in the pathogenesis of primary and secondary haemophagocytic lymphohistiocytosis: differences and similarities. $B r \quad J$ Haematol. 2016;174(2):203-217. doi:10.1111/bjh.14147

11. Al-Samkari H, Berliner N. Hemophagocytic Lymphohistiocytosis. Annu Rev Pathol. 2018;13(1):27-49. doi:10.1146/annurev-pathol $-020117-043625$

12. Yildiz H, Bailly S, Van Den Neste E, Yombi JC. Clinical management of relapsed/refractory hemophagocytic lymphohistiocytosis in adult patients: a review of current strategies and emerging therapies. Ther Clin Risk Manag. 2021;17:293-304. doi:10.2147/TCRM. S195538

13. Debaugnies F, Mahadeb B, Ferster A, et al. Performances of the $\mathrm{H}$-score for diagnosis of hemophagocytic lymphohistiocytosis in adult and pediatric patients. Am J Clin Pathol. 2016;145 (6):862-870. doi:10.1093/ajcp/aqw076

14. Lerolle N, Laanani M, Riviere S, et al. Diversity and combinations of infectious agents in 38 adults with an infection-triggered reactive haemophagocytic syndrome: a multicenter study. Clin Microbiol Infect. 2016;22(3):268.e1-8. doi:10.1016/j.cmi.2015.11.018

15. Zhuo WB, Gao Y, Yang CY, et al. Clinical characteristics of hemophagocytic syndrome: analysis of 46 cases. Nan Fang Yi Ke Da Xue Хие Bao. 2018;38(6):769-insideback cover. Chinese.

16. Gao WB, Shi MJ, Song XJ, Yang J, Zhu JH. Clinical analysis of 81 adult patients with hemophagocytic lymphohistiocytosis. Zhonghua Xue Ye Xue Za Zhi. 2020;41(3):248-250. Chinese.

17. Pei R, Wang Z, Wang Y, et al. A multicenter retrospective etiological analysis of 601 patients with hemophagocytic lymphohistiocytosis in China. Zhonghua Nei Ke Za Zhi. 2015;54 (12):1018-1022. Chinese.
18. Lachmann G, Spies C, Schenk T, Brunkhorst FM, Balzer F, La Rosee P. Hemophagocytic lymphohistiocytosis: potentially underdiagnosed in intensive care units. Shock. 2018;50(2):149-155. doi:10.1097/SHK.0000000000001048

19. La Rosee P, Horne A, Hines M, et al. Recommendations for the management of hemophagocytic lymphohistiocytosis in adults. Blood. 2019;133(23):2465-2477. doi:10.1182/blood.2018894618

20. Schram AM, Berliner N. How I treat hemophagocytic lymphohistiocytosis in the adult patient. Blood. 2015;125(19):2908-2914. doi:10.1182/blood-2015-01-551622

21. Yin G, Man C, Huang J, et al. The prognostic role of plasma fibrinogen in adult secondary hemophagocytic lymphohistiocytosis. Orphanet J Rare Dis. 2020;15(1):332. doi:10.1186/s13023-02001622-2

22. Apodaca E, Rodriguez-Rodriguez S, Tuna-Aguilar EJ, DemichelisGomez R. Prognostic factors and outcomes in adults with secondary hemophagocytic lymphohistiocytosis: a single-center experience. Clin Lymphoma Myeloma Leuk. 2018;18(10):e373-e380. doi:10.1016/j.clml.2018.06.014

23. Parikh SA, Kapoor P, Letendre L, Kumar S, Wolanskyj AP. Prognostic factors and outcomes of adults with hemophagocytic lymphohistiocytosis. Mayo Clin Proc. 2014;89(4):484-492. doi:10.1016/j.mayocp.2013.12.012

24. Henry BM, Aggarwal G, Wong J, et al. Lactate dehydrogenase levels predict coronavirus disease 2019 (COVID-19) severity and mortality: a pooled analysis. Am J Emerg Med. 2020;38(9):1722-1726. doi:10.1016/j.ajem.2020.05.073

25. Xiao W, Liu W, Yin L, et al. Serum hydroxybutyrate dehydrogenase as an early predictive marker of the severity of acute pancreatitis: a retrospective study. BMC Gastroenterol. 2020;20(1):393. doi:10.1186/s12876-020-01521-7

26. Cui J, Xiong J, Zhang Y, et al. Serum lactate dehydrogenase is predictive of persistent organ failure in acute pancreatitis. $J$ Crit Care. 2017;41:161-165. doi:10.1016/j.jcrc.2017.05.001

27. Lagana G, Barreca D, Calderaro A, Bellocco E. Lactate dehydrogenase inhibition: biochemical relevance and therapeutical potential. Curr Med Chem. 2019;26(18):3242-3252. doi:10.2174/ 0929867324666170209103444

28. Knaak C, Nyvlt P, Schuster FS, et al. Hemophagocytic lymphohistiocytosis in critically ill patients: diagnostic reliability of HLH-2004 criteria and HScore. Crit Care. 2020;24(1):244. doi:10.1186/s13054020-02941-3
International Journal of General Medicine

\section{Publish your work in this journal}

The International Journal of General Medicine is an international, peer-reviewed open-access journal that focuses on general and internal medicine, pathogenesis, epidemiology, diagnosis, monitoring and treatment protocols. The journal is characterized by the rapid reporting of reviews, original research and clinical studies across all disease areas. The manuscript management system is completely online and includes a very quick and fair peer-review system, which is all easy to use. Visit http://www.dovepress.com/ testimonials.php to read real quotes from published authors. 